\title{
Influence of Heat Treatment on the Quality of Functional Gluten-Free Spaghetti
}

\author{
Marcella Mastromatteo $^{1}$, Stefania Chillo ${ }^{1}$, Mariapia Iannetti ${ }^{1}$, Valentina Civica ${ }^{1}$, Grazia Sepielli ${ }^{2}$, \\ Matteo Alessandro Del Nobile ${ }^{1,2}$ \\ ${ }^{1}$ Institute of Research and Biotechnological Applications for Security and Promotion of Local and Quality Products, University of \\ Foggia, Foggia, Italy; ${ }^{2}$ Department of Food Science, University of Foggia, Foggia, Italy. \\ Email: ma.delnobile@unifg.it
}

Received November $16^{\text {th }}, 2011$; revised January $4^{\text {th }}, 2012$; accepted January $14^{\text {th }}, 2012$

\begin{abstract}
In this study the influence of initial water content and the extent of flour thermal pre-treatment on both the dough rheological properties and the sensorial attributes of maize and chickpeas based gluten-free spaghetti were assessed. Results showed that samples with the highest initial water content had the highest values of elongation and shear viscosity, therefore dough with greater extensibility was obtained. Regarding the sensorial properties of non-cooked spaghetti, the overall quality of all samples had a very positive score with the exception of the samples with the highest initial water content and the lowest steam injection time that were scored just above the acceptability threshold because of their low resistance to break. The overall quality values of the cooked dry spaghetti were found to be around the acceptability threshold with the exception of the sample with the highest initial water content that showed a value higher than the threshold due to the highest values of bulkiness and adhesiveness.
\end{abstract}

Keywords: Functional Food; Rheological Properties; Sensory Analysis

\section{Introduction}

Pasta, a traditional food with origins from the first century $\mathrm{BC}[1]$, is popular for its ease of cooking and its nutritional qualities. The most appropriate cereal for the production of high quality pasta products is durum wheat (Triticum durum) [2]. The intrinsic quality attributes of the pasta are influenced primarily by the properties of the protein and starch fraction and by factors such as the origin of the semolina [3], and the pasta production process (mixing, extrusion and drying conditions) [4]. In pasta processing, gluten is mainly responsible for the formation of the structure. Gluten is considered to be the most significant factor related to pasta cooking quality [5]. However, some people with a specific genetic nature suffer from celiac disease upon consumption of food containing wheat, rye or barley [6] and a strict glutenfree diet is currently the only treatment for that disease. Huang et al. [7] produced non-gluten pasta with characteristics most similar to wheat-based pasta containing higher levels of modified starch, xanthan gum and locust bean gum.

In the last decades consumer demands in the field of food production have changed considerably. Consumers more and more believe that foods contribute directly to their health [8]. Today foods are not intended to only satisfy hunger and to provide necessary nutrients for humans but also to prevent nutrition-related diseases and improve physical and mental well-being of the consumers [9]. In this regard, functional foods play an outstanding role. Pasta products can be fortified with supplements from various high protein sources to improve their nutritional properties. Results from a number of recent studies have highlighted the need for an improvement in the nutritional quality of cereal based gluten-free products. Several gluten-free grains exist, such as the pseudocereals amaranth, quinoa and buckwheat; these are characterized by an excellent nutrient profile. Thus, an increasing trend in research is focusing on their use in the formulation of high quality, healthy gluten-free products such as bread and pasta. However, commercialization of these products is still quite limited. The availability of palatable pseudocereal-containing gluten-free products would represent a significant advance towards ensuring an adequate intake of nutrients in subjects with celiac disease [10].

Chickpeas (Cicer arietinum) are a good source of proteins and carbohydrates, possessing important quantities of some vitamins (thiamin, niacin), minerals $(\mathrm{Ca}, \mathrm{P}, \mathrm{Fe}$, $\mathrm{Mg}, \mathrm{K}$ ) and unsaturated fatty acids (oleic, linoleic). However, chickpeas have several undesirable attributes, such 
as long cooking times, enzyme inhibitors, phytates, flatus factors, and phenolic compounds, which must be removed or eliminated for effective utilization; furthermore, chickpeas proteins are deficient in sulfur amino acids [11]. The water absorption capacity of chickpeas flour is found to be higher than that of wheat flour $[12,13]$.

Maize flour is derived from grounded and desiccated seed of the maize plant (also commonly called corn in many English countries), Zea mays. It is the second most produced and consumed flour after wheat flour, competing with rice flour. Maize contains $7-13 \mathrm{~g} / 100 \mathrm{~g}$ proteins, is uniquely rich in dietary fibre, vitamin B6, magnesium and it has very low fat content [14].

When cereals and legumes are combined, the quality score of the combined proteins may be much higher than each of the individual values [15]. The incorporation of chickpea flour also increased the mineral and fat contents of pasta, contributing to elevate the nutritional value of the food.

To obtain pasta of good quality from new meals it is often necessary to modify the traditional manufacture process [16]. In particular, the additive use and/or an adequate technological production process have to be adopted to counteract any changes in the rheological properties [17]. Significant studies have been carried out on gluten-free products involving diverse approaches which have included the use of additives such as starches, hydrocolloids, dairy products, gums and other non-gluten proteins, prebiotics and combinations, as alternatives to gluten, to improve the structure, texture, acceptability and shelf-life of gluten-free products [18]. Alternatively, the production process can be change by applying a heat-moisture treatment on processed flour. The hydration of flour is crucial in the food industry, because it affects its functional properties and the quality of cooking products (bread, cookies, etc). The water absorption capacity of flour often defines its quality and its aptitude to form viscoelastic dough. The hydration properties of wheat flour are considered as a critical factor that partly controls how flours may be stored and processed, as well as the quality of processed products. Mechanisms involved in hydration of wheat flour particles, changes in microstructure of biopolymers, and kinetics of dough formation still constitute an important field of investigation [19]. Hoover and Manuel [20] investigated the nature and extent of interactions of maize starches during heat-moisture treatment and found that the starch chain interactions occurred within both the amorphous and crystalline regions of the granule. They also reported that the extent of starch re-associations were greater in the amorphous region due to the interactions of amyloseamylose, amylose-lipid, and amylose-amylopectin. Although the crystalline order altered during heat-moisture treatment, the interactions between amylo-pectin chains in crystalline regions occur only to a limited extent $[20$, 21].

The aim of this research was to evaluate the influence of water content and the extent of flour thermal pretreatment on dough rheological properties and sensorial quality of maize and chickpea based gluten-free nonconventional dry spaghetti.

\section{Materials and Methods}

\subsection{Spaghetti Preparation}

Maize and chickpea flours were bought from Bongiovanni mill (Mondovì, Cuneo, Italy). To prepare the dough samples, $50 \%$ of maize flour and $50 \%$ of chickpea flour were mixed. The dough based on maize flour $(100 \%)$ was manufactured and then used as a reference (CTRL). Moreover, two commercially available spaghetti, one in base of maize flour (Molino di Ferro, Treviso, Italy) named as CM1 and one based on maize and rice flour with pea protein isolate named as CM2 (Schär, Sondrio, Italy) were also used as reference. A steam cooker (LT50 2E Namad, Rome, Italy) was used to prepare the dough. It is made of a stainless steel bathtub and a crankshaft equipped with paddles constructed entirely of stainless steel, some of which are perforated to allow the release of steam in the dough. In particular, water was added to the flours, previously mixed, and kneaded for $20 \mathrm{~min}$, afterwards saturated steam was injected inside the dough at temperature of $110^{\circ} \mathrm{C}$ and pressure of 4.5 bar. The process conditions applied are listed in Table 1. In particular, the amount of flour used was fixed at $5000 \mathrm{~g}$; knowing the injection time and mass rate of steam and fixing the ratio between mass of flour (Mf) and mass of water added to the flour (i.e., the sum of mass of initial water and steam $(\mathrm{Mw}+\mathrm{Ms}))$, the initial water content to be added to the flours prior to steam injection, named as IWC, for different times of steam injection was calculated. Then, an experimental design with the variables IWC and steam injection time was performed.

Dry spaghetti samples were produced by means of a pilot plant made of an extruder (60VR, Namad, Rome, Italy) and a dryer (SG600, Namad, Rome, Italy). The extruder was equipped with a screw (length $30 \mathrm{~cm}$, diameter $5.5 \mathrm{~cm}$ ), which ended with a bronze die (diameter hole of $1.70 \mathrm{~mm}$ ). The screw speed was $50 \mathrm{rev} / \mathrm{min}$. The process conditions applied were the following: drying temperature I step $50^{\circ} \mathrm{C}$, drying time I step $80 \mathrm{~min}$, drying temperature II step $60^{\circ} \mathrm{C}$, drying time II step $240 \mathrm{~min}$, drying temperature III step $70^{\circ} \mathrm{C}$, drying time III step 60 min.

\subsection{Dough Rheological Properties}

Elongation and shear viscosity of each dough sample 
Table 1. Process conditions used to manufacture the dough samples.

\begin{tabular}{ccccccc}
\hline Samples & Steam injection speed $(\mathrm{g} / \mathrm{min})$ & Steam injection time $(\mathrm{min})$ & $\mathrm{Mf} /(\mathrm{MW}+\mathrm{Ms})^{\mathrm{a}}$ & $\mathrm{IWC}^{\mathrm{b}}(\mathrm{g})$ & $\mathrm{TWC}^{\mathrm{c}}(\mathrm{g})$ & $\mathrm{IWC}^{\mathrm{d}}(\%)$ \\
\hline A & 54.6 & 5 & 2.2 & 2000 & 2273 & 40.00 \\
B & 54.6 & 12 & 2.2 & 1618 & 2273.2 & 32.40 \\
C & 54.6 & 19 & 2.2 & 1235 & 2272.4 & 24.70 \\
D & 54.6 & 5 & 2.3 & 1900 & 2173 & 38.00 \\
E & 54.6 & 12 & 2.3 & 1519 & 2174.2 & 30.40 \\
F & 54.6 & 19 & 2.3 & 1137 & 2174.4 & 22.70 \\
G & 54.6 & 5 & 2.4 & 1810 & 2083 & 36.20 \\
H & 54.6 & 12 & 2.4 & 1428 & 2083.2 \\
I & 54.6 & 19 & 2.4 & 1046 & 2083.4 & 20.90 \\
\hline
\end{tabular}

${ }^{\mathrm{a}}$ Ratio between mass of flour and the sum of mass of water and steam; ${ }^{\mathrm{b}}$ Initial water content; ${ }^{\mathrm{c}}$ Total water content (IWC + steam); ${ }^{\mathrm{d}_{\%}} \mathrm{w} / \mathrm{w}$ flour basis.

were investigated by means of a Rosand capillary rheometer (Malvern Instruments, Malvern, Worcester, UK) with twin cylinders. Two different length dies with the same diameter $(1 \mathrm{~mm})$ were selected to measure the entry pressure losses. The length of left die was of $10 \mathrm{~mm}$ and the pressure was of 10 psi. Whereas, the length of right die was of $0.25 \mathrm{~mm}$ and the pressure was of $150 \mathrm{psi}$. The experiments were carried out at a temperature of $30^{\circ} \mathrm{C}$ and at shear rate between $10-2000 \mathrm{~s}^{-1}$. The rheological behaviour is studied using the following power law model that satisfactory fitted the experimental data:

$$
\tau_{S}=K \cdot \dot{\gamma}_{S}^{n}
$$

and

$$
\tau_{e}=L \cdot \dot{\gamma}_{e}^{m}
$$

where $\tau_{s}$ and $\tau_{e}$ are the shear stress $[\mathrm{Pa}]$ and extensional stress $[\mathrm{kPa}], K$ and $L$ are the consistency indices $\left[\mathrm{Pa} \cdot s^{n}\right.$ and $\mathrm{kPa} \cdot \mathrm{s}^{\mathrm{n}}$, respectively], the $\dot{\gamma}_{\mathrm{s}}$ and $\dot{\gamma}_{e}$ are the shear and extension rate [1/s], and $\mathrm{n}$ and $\mathrm{m}$ are the flow indices (dimensionless). The elongation and shear viscosity $\left(\eta_{e}\right.$ and $\eta_{s}$, respectively) were calculated on the range of shear and extension rate tested by using the following power law model $[22,23]$ :

$$
\eta_{S}=K \cdot \dot{\gamma}_{S}^{n-1}
$$

and

$$
\eta_{e}=L \cdot \dot{\gamma}_{e}^{m-1}
$$

The Bagley correction was applied to all data from Rosand rheometer. Three measurements of the viscosity experiment were performed on each sample.

\subsection{Sensory Analysis}

The sensorial quality of non-cooked and cooked dry spaghetti was evaluated by means of a panel of ten trained panelists. The panelists were selected on the basis of their interest in the sensory evaluation of pasta, and trained by testing commercial conventional and glutenfree spaghetti.

Each spaghetti sample was cooked at different times and tested by the panel to estimate the optimal cooking time (OCT), which was $8 \mathrm{~min}$ for the CTRL and CM1 reference samples, $11 \mathrm{~min}$ for the CM2 reference sample and $7 \mathrm{~min}$ for the other samples. The panelists were asked to evaluate color, odor, homogeneity, and resistance to break of non-cooked dry spaghetti. They were also asked to score the non-cooked dry spaghetti overall quality on the base of the abovementioned attributes. Elasticity, firmness, bulkiness, adhesiveness, color, odor, and taste of cooked dry spaghetti were also evaluated. Also in this case the panelists were asked to score the cooked dry spaghetti overall quality on the base of the abovementioned attributes.

To this aim, a nine-point hedonic rating scale, where 1 corresponded to extremely unpleasant, 9 to extremely pleasant and 5 to satisfactory (acceptability threshold) was used [24].

\subsection{Statistical Analysis}

The rheological and sensorial properties of spaghetti based on maize and chickpea flours as affected by the initial water content and the steam injection time were evaluated in this study. In particular, the influence of the initial water content and the steam injection time on the spaghetti quality was studied by modulating the two selected variables according to an experimental design. The lowest and highest levels of independent variables studied were chosen from results of preliminary laboratory tests. A statistical software (StatSoft, Inc, Tulsa, OK, USA) was used to generate surface response plots that permitted evaluation of the linear, quadratic and interact- 
tive effects of the independent variables on the selected dependent variables $(\mathrm{p}<0.05)$. Moreover, the results of the rheological and sensorial analysis were compared by a one-way variance analysis (ANOVA). A Duncan's multiple range test, with the option of homogeneous groups $(p<0.05)$, was carried out to determine significant differences between spaghetti samples. STATISTICA 7.1 for Windows (StatSoft, Inc, Tulsa, OK, USA) was used for this aim.

\section{Results and Discussion}

In the following, the rheological and sensorial properties of gluten-free spaghetti based on maize and chickpeas flours were presented and discussed separately. Results show how the water and heat diffusion during the kneading process affect the sensorial and textural properties of the manufactured spaghetti.

\subsection{Rheological Measurement}

During the kneading process, different physical, chemical and structural changes take place, for example diffusion of heat and water. The thermal treatment, such as steam injection, and the interaction between the heating rate and the initial water content might affect the structural and rheological properties of dough, which are directly correlated to the quality of the final product.

Figure 1 show elongation and shear viscosity as a function of extension rate and shear rate, respectively. As can be inferred from these figures, the viscosity increases with shear rate showing a shear-thickening behavior of the dough [25].

From Figure 1 it can be inferred that the $\mathrm{H}$ and CTRL samples show the higher value of elongation viscosity with respect to the other samples, while the lowest value was recorded for the A and D samples. Coherently, the consistency index L (Table 2), obtained by fitting Equation (2) to the experimental data, showed the highest values for the $H$ and CTRL samples and the lowest values for the A and D samples. The B, E and G samples showed elongation viscosity values between those previously mentioned. Moreover, Figure 1 highlights that samples $\mathrm{E}$ and $\mathrm{H}$ had the highest value of shear viscosity among the tested samples, whereas the A sample had the lowest value. Analogous consideration can be drawn from data listed in Table 2. In fact, samples $\mathrm{E}$ and $\mathrm{H}$ have the highest value of the consistency index $\mathrm{K}$, which was obtained by fitting Equation (1) to the experimental data, whereas for sample $A$ the lowest value was observed. The B, G, D and CTRL samples had a behavior bracketed between that of samples E, H and A. The obtained results highlights that the high initial water content has a softening effect. This is in agreement with what reported in the literature by Lètang et al. [26]. They

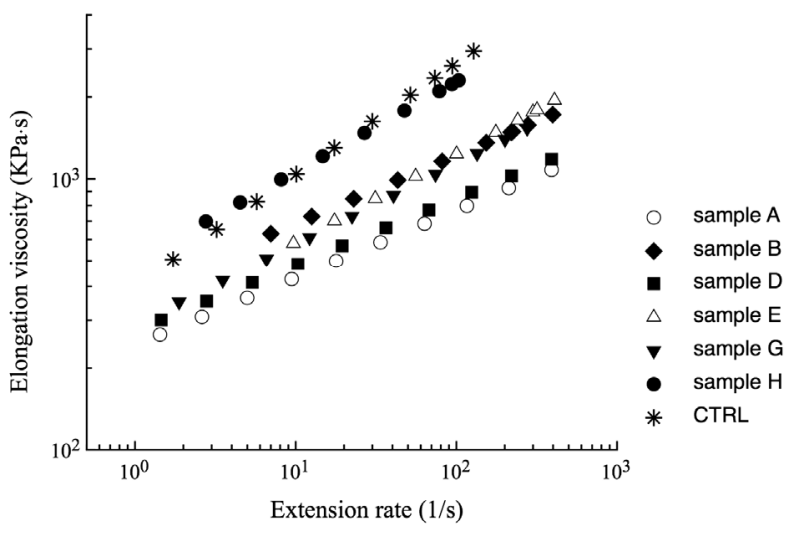

(a)

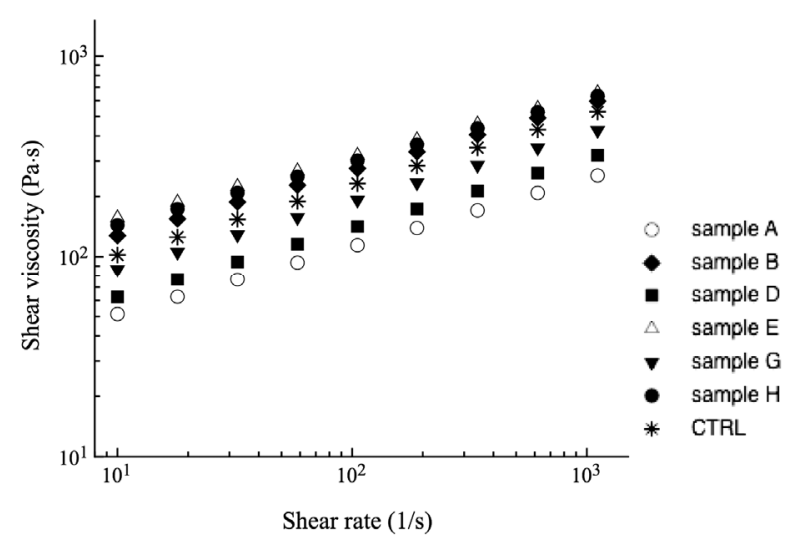

(b)

Figure 1. Elongation viscosity as a function of extension rate (a) and shear viscosity as a function of shear rate (b) for all manufactured spaghetti samples.

Table 2. Values of the consistency indices ( $L$ and $K$ ) and the flow indices ( $m$ and $n$ ) obtained by fitting Equations (1) and (2) to the experimental data.

\begin{tabular}{ccccc}
\hline & $\boldsymbol{L}$ & $\boldsymbol{m}$ & $\boldsymbol{K}$ & $\boldsymbol{n}$ \\
\hline A & $242.9624^{\mathrm{b}}$ & $1.2499^{\mathrm{a}}$ & $23.495^{\mathrm{a}}$ & $1.3396^{\mathrm{a}}$ \\
B & $387.5415^{\mathrm{d}}$ & $1.2492^{\mathrm{a}}$ & $60.072^{\mathrm{e}}$ & $1.3273^{\mathrm{c}}$ \\
D & $274.5536^{\mathrm{a}}$ & $1.2445^{\mathrm{a}}$ & $28.185^{\mathrm{b}}$ & $1.3667^{\mathrm{a}}$ \\
E & $278.4722^{\mathrm{a}}$ & $1.3235^{\mathrm{b}}$ & $77.683^{\mathrm{g}}$ & $1.3044^{\mathrm{b}}$ \\
G & $290.7003^{\mathrm{c}}$ & $1.296^{\mathrm{c}}$ & $39.619^{\mathrm{c}}$ & $1.3388^{\mathrm{a}}$ \\
H & $499.8878^{\mathrm{f}}$ & $1.3292^{\mathrm{b}}$ & $69.832^{\mathrm{f}}$ & $1.3144^{\mathrm{b}}$ \\
CTRL & $404.6360^{\mathrm{e}}$ & $1.4091^{\mathrm{d}}$ & $45.7749^{\mathrm{d}}$ & $1.3486^{\mathrm{a}}$ \\
\hline
\end{tabular}

${ }^{\mathrm{a}-\mathrm{g}}$ Means in the same column followed by different superscripts are significantly different $(\mathrm{p}<0.05)$

found that an increase of water content or mixing time had softening effect, in one case because of the decrease of the intermolecular forces along polymer chains, by acting the water as plasticizer; in the second case because of the breaking of disulfide bonds and the production of 
smaller molecules that cause a lower consistency. Moreover, results showed that the highest steam injection time does not compensate the lowest IWC in terms of softness of dough. In fact, it is worth noting that it was not possible to perform rheological measurements on samples $\mathrm{C}$, $\mathrm{F}$ and I, which have the lowest IWC and the longest steam injection time, because of high firmness of these doughs. Mechanisms involved in initial hydration of flour particles cause changes in microstructure of biopolymers, and kinetics of dough formation [19]. In particular, during the hydration process, a continuous hydrated matrix between particles is developed. In the case of a dough optimal hydration, the flour particles were not visible but masked by a continuous "gel" [12]. Most probably, the low water content did permit a good initial hydration of the dough and then also the higher steam injection time had no effect. Moreover, in this case, the initial water is not sufficient to allow starch gelatinization upon steam injection, and this affects its aptitude to form viscoelastic doughs [27]. In fact, as reported by Hsieh et al. [28] the dough viscosity is directly influenced by the degree of gelatinization of the materials. The process of gelatinization of starch from the starch granules is made possible by heating in aqueous media. Under these conditions the starch granules, hydrating gradually swell, starch loses its crystalline structure; amylopectin and amylose enter into solution, forming bonds with water molecules. During the gelatinization process water diffuses into the porous structure of dough and the gelatinization of starch proceeds from the bounds of the product to be swelled (gelled zone) towards the inside of the product, not yet interested in the diffusion and gelatinization [29-31]. In this case, the position of the front area of advancement of gelled changes over time and the feed rate depends on the interaction between starch and water that occurs at the interface separating the two zones. Therefore, an increase of IWC gives a more extensible sample, which might mean that water acts as a plasticizer reducing the starch melting point, as was proposed by Della Valle et al. [32]. On the other hand, dough with higher firmness was obtained with an intermediate value of IWC and steam injection time. In the latter case, the IWC and the thermal treatment to which the dough samples were subjected during the kneading process allowed the formation of a strong physical network, responsible for the higher strength of dough.

\subsection{Sensory Analysis}

The sensorial properties of dry spaghetti samples, cooked and non-cooked, are listed in Tables 3. Regarding the non-cooked spaghetti, all samples had a very positive score of overall quality and they are statistically similar to the CTRL and CM2 samples. On the other hand, the A, $\mathrm{D}$ and $\mathrm{G}$ samples were scored just above the acceptability threshold because of the low resistance to break value. Moreover, they are similar to the CM1 reference sample. This result seems to be correlated to what obtained for the rheological properties. In fact A, D and G samples showed the lowest values of the elongation and shear

Table 3. Sensory characteristics of dry cooked and non-cooked spaghetti samples.

\begin{tabular}{|c|c|c|c|c|c|c|c|c|c|c|c|c|}
\hline \multirow{2}{*}{ Samples } & \multicolumn{4}{|c|}{ Non-cooked spaghetti } & \multicolumn{8}{|c|}{ Cooked spaghetti } \\
\hline & Color & Homogeneity & $\begin{array}{l}\text { Resistance } \\
\text { to break }\end{array}$ & $\begin{array}{l}\text { Overall } \\
\text { quality }\end{array}$ & Elasticity & Firmness & Bulkiness & Adhesiveness & Color & Odor & Taste & $\begin{array}{l}\text { Overall } \\
\text { quality }\end{array}$ \\
\hline A & $6.0^{c} \pm 0.3$ & $7.7^{\mathrm{a}, \mathrm{c}} \pm 0.4$ & $5.4^{\mathrm{c}} \pm 0.4$ & $5.9^{\mathrm{b}, \mathrm{c}} \pm 0.2$ & $6.0^{\mathrm{a}, \mathrm{b}} \pm 0.9$ & $6.6^{\mathrm{a}, \mathrm{b}} \pm 0.4$ & $7.8^{\mathrm{f}, \mathrm{g}} \pm 0.2$ & $7.8^{\mathrm{b}} \pm 0.2$ & $6.5^{\mathrm{a}, \mathrm{b}, \mathrm{c}} \pm 0.3$ & $6.9^{\mathrm{a}} \pm 0.6$ & $6.6^{\mathrm{c}} \pm 0.4$ & $6.3^{\mathrm{f}} \pm 0.2$ \\
\hline $\mathrm{B}$ & $7.7^{\mathrm{a}} \pm 0.4$ & $8.4^{\mathrm{b}, \mathrm{d}} \pm 0.5$ & $7.7^{\mathrm{a}, \mathrm{b}} \pm 0.2$ & $7.8^{\mathrm{a}} \pm 0.4$ & $6.0^{\mathrm{a}, \mathrm{b}} \pm 0.9$ & $5.2^{\mathrm{d}} \pm 0.2$ & $4.3^{\mathrm{a}, \mathrm{b}} \pm 0.2$ & $3.8^{\mathrm{a}} \pm 0.5$ & $7.8^{\mathrm{f}, \mathrm{g}} \pm 0.2$ & $6.7^{\mathrm{a}} \pm 0.5$ & $5.2^{\mathrm{a}} \pm 0.2$ & $4.3^{\mathrm{a}, \mathrm{c}} \pm 0.2$ \\
\hline $\mathrm{C}$ & $7.9^{\mathrm{a}} \pm 0.2$ & $8.8^{\mathrm{d}} \pm 0.4$ & $7.8^{\mathrm{a}, \mathrm{b}} \pm 0.2$ & $8.1^{a} \pm 0.2$ & $5.6^{\mathrm{a}, \mathrm{b}} \pm 1.3$ & $6.3^{\mathrm{a}} \pm 0.2$ & $4.4^{\mathrm{a}, \mathrm{c}} \pm 0.4$ & $3.9^{\mathrm{a}} \pm 0.4$ & $7.7^{\mathrm{e}, \mathrm{f,g}} \pm 0.4$ & $6.8^{\mathrm{a}} \pm 0.5$ & $5.6^{\mathrm{a}} \pm 0.45$ & $5.3^{\mathrm{d}, \mathrm{e}} \pm 0.2$ \\
\hline $\mathrm{D}$ & $5.9^{\mathrm{c}} \pm 0.4$ & $7.7^{\mathrm{a}, \mathrm{c}} \pm 0.4$ & $5.3^{\mathrm{c}} \pm 0.2$ & $5.7^{\mathrm{b}} \pm 0.2$ & $6.1^{\mathrm{a}, \mathrm{b}} \pm 1.3$ & $6.3^{a} \pm 0.2$ & $7.3^{\mathrm{f}} \pm 0.2$ & $7.5^{\mathrm{b}} \pm 0.3$ & $6.6^{\mathrm{a}, \mathrm{b}, \mathrm{c}} \pm 0.4$ & $6.8^{\mathrm{a}} \pm 0.6$ & $5.9^{\mathrm{a}} \pm 0.6$ & $5.5^{\mathrm{e}} \pm 0.3$ \\
\hline $\mathrm{E}$ & $8.0^{\mathrm{a}} \pm 0.0$ & $8.0^{\mathrm{a}, \mathrm{b}} \pm 0.0$ & $7.7^{\mathrm{a}, \mathrm{b}} \pm 0.2$ & $7.8^{\mathrm{a}} \pm 0.2$ & $5.3^{\mathrm{a}} \pm 1.3$ & $6.5^{\mathrm{a}, \mathrm{b}} \pm 0.3$ & $4.4^{\mathrm{a}, \mathrm{c}} \pm 0.2$ & $4.0^{\mathrm{a}} \pm 0.0$ & $7.1^{\mathrm{c}, \mathrm{d}, \mathrm{e}} \pm 0.2$ & $6.4^{\mathrm{a}} \pm 0.2$ & $5.5^{\mathrm{a}} \pm 0.3$ & $4.2^{\mathrm{a}} \pm 0.2$ \\
\hline $\mathrm{F}$ & $8.0^{\mathrm{a}} \pm 0.0$ & $8.0^{\mathrm{a}, \mathrm{b}} \pm 0.0$ & $7.8^{\mathrm{a}, \mathrm{b}} \pm 0.2$ & $7.9^{\mathrm{a}} \pm 0.2$ & $5.6^{\mathrm{a}, \mathrm{b}} \pm 1.2$ & $6.4^{\mathrm{a}, \mathrm{b}} \pm 0.4$ & $4.1^{\mathrm{a}, \mathrm{b}} \pm 0.2$ & $3.8^{\mathrm{a}} \pm 0.2$ & $7.0^{\mathrm{b}, c, \mathrm{~d}} \pm 0.0$ & $6.4^{\mathrm{a}} \pm 0.4$ & $5.7^{\mathrm{a}} \pm 0.2$ & $4.2^{\mathrm{a}} \pm 0.2$ \\
\hline G & $6.0^{c} \pm 0.3$ & $7.3^{\mathrm{c}} \pm 0.4$ & $5.1^{\mathrm{c}} \pm 0.4$ & $6.0^{\mathrm{b}, \mathrm{c}} \pm 0.3$ & $36.0^{\mathrm{a}, \mathrm{b}} \pm 0.9$ & $6.3^{\mathrm{a}} \pm 0.2$ & $5.0^{\mathrm{c}} \pm 0.6$ & $4.9^{c} \pm 0.5$ & $6.3^{\mathrm{a}} \pm 0.2$ & $6.4^{\mathrm{a}} \pm 0.4$ & $5.6^{\mathrm{a}} \pm 0.2$ & $4.8^{\mathrm{c}, \mathrm{d}} \pm 0.6$ \\
\hline $\mathrm{H}$ & $7.3^{\mathrm{a}, \mathrm{b}} \pm 0.4$ & $8.0^{\mathrm{a}, \mathrm{b}} \pm 0.0$ & $7.4^{\mathrm{a}} \pm 0.2$ & $7.6^{\mathrm{a}} \pm 0.4$ & $5.5^{\mathrm{a}, \mathrm{b}} \pm 1.0$ & $6.7^{a . b} \pm 0.2$ & $3.7^{\mathrm{b}, \mathrm{e}} \pm 0.2$ & $3.8^{\mathrm{a}} \pm 0.2$ & $6.8^{\mathrm{a}, \mathrm{b}, \mathrm{c}, \mathrm{d}} \pm 0.2$ & $6.5^{a} \pm 0.3$ & $5.6^{\mathrm{a}} \pm 0.4$ & $4.0^{\mathrm{a}} \pm 0.3$ \\
\hline I & $7.6^{\mathrm{a}, \mathrm{b}} \pm 0.4$ & $8.0^{\mathrm{a}, \mathrm{b}} \pm 0.0$ & $7.4^{\mathrm{a}} \pm 0.4$ & $8.0^{\mathrm{a}} \pm 0.0$ & $5.3^{\mathrm{a}} \pm 1.0$ & $6.3^{\mathrm{a}} \pm 0.2$ & $3.2^{\mathrm{e}} \pm 0.2$ & $3.4^{\mathrm{a}} \pm 0.4$ & $6.4^{\mathrm{a}, \mathrm{b}} \pm 0.4$ & $6.5^{\mathrm{a}} \pm 0.3$ & $5.5^{\mathrm{a}} \pm 0.5$ & $3.7^{\mathrm{a}} \pm 0.2$ \\
\hline CTRL & $8.0^{\mathrm{a}} \pm 0.0$ & $6.3^{\mathrm{a}, \mathrm{c}} \pm 0.5$ & $7.5^{\mathrm{a}, \mathrm{b}} \pm 0.4$ & $7.4^{\mathrm{a}} \pm 0.4$ & $5.7^{\mathrm{a}, \mathrm{b}} \pm 0.5$ & $7.4^{\mathrm{c}} \pm 0.6$ & $8.6^{\mathrm{d}} \pm 0.6$ & $7.5^{\mathrm{b}} \pm 0.4$ & $8.0^{\mathrm{g}} \pm 0.0$ & $8.0^{b} \pm 0.0$ & $8.0^{b} \pm 0.0$ & $7.6^{\mathrm{b}} \pm 0.4$ \\
\hline CM1 & $7.0^{\mathrm{b}} \pm 0.5$ & $4.0^{\mathrm{e}} \pm 0.0$ & $8.0^{\mathrm{b}} \pm 0.0$ & $6.6^{\mathrm{c}} \pm 0.6$ & $7.0^{\mathrm{a}, \mathrm{b}} \pm 0.0$ & $7.0^{b, c} \pm 0.0$ & $8.0^{\mathrm{d}, \mathrm{g}} \pm 0.0$ & $7.3^{\mathrm{b}} \pm 0.6$ & $6.6^{\mathrm{a}, \mathrm{b}, \mathrm{c}} \pm 0.6$ & $7.0^{\mathrm{a}} \pm 0.5$ & $7.3^{\mathrm{b}} \pm 0.6$ & $7.2^{b} \pm 0.3$ \\
\hline $\mathrm{CM} 2$ & $7.3^{\mathrm{a}, \mathrm{b}} \pm 0.7$ & $6.6^{\mathrm{f}} \pm 0.7$ & $8.0^{\mathrm{b}} \pm 0.0$ & $7.5^{\mathrm{a}} \pm 1.0$ & $7.3^{b} \pm 0.7$ & $7.5^{\mathrm{c}} \pm 0.5$ & $8.6^{\mathrm{d}} \pm 0.6$ & $7.7^{b} \pm 0.3$ & $7.3^{\mathrm{de}, \mathrm{e} f} \pm 0.7$ & $7.2^{\mathrm{a}} \pm 0.3$ & $7.5^{\mathrm{b}} \pm 0.5$ & $7.5^{\mathrm{b}} \pm 0.5$ \\
\hline
\end{tabular}

\footnotetext{
${ }^{\mathrm{a}-\mathrm{g}}$ Means in the same column followed by different superscripts are significantly different $(\mathrm{p}<0.05)$.
} 
viscosity, and, consequently, the lowest values of the consistency index among the other samples.

The resistance to break of dry spaghetti could be related to several process parameters such as rheological properties of the dough, spaghetti composition, and thermal treatment to which the spaghetti samples were subjected during the drying process. In this case, most probably the dough hydration, in terms of both IWC and steam injection time, was the main factor affecting the quality of processed products; in fact, the formation of a strong physical network depends from the available water content in the dough. The surface response plot was generated to better illustrate the dependences between the selected variables (Figure 2). As can be observed from the above figure, the overall quality of non-cooked spaghetti increases with the increase of both IWC and steam injection time.

Regarding the cooked spaghetti, the overall quality values of tested samples were found to be around the acceptability threshold with the exception of the A sample, whose score was significantly different from the other samples, showing an overall quality value higher that the threshold. In particular, the highest values of bulkiness and adhesiveness improved the overall quality of sample A. It is worth noting that the bulkiness and adhesiveness score for A sample did not differ significantly from that of reference samples. The adhesiveness is related to the amount of water absorbed by the matrix during the cooking process. As reported in literature, as the temperature increases the starch granules start to swell and absorb water. In a high water content medium it is easier for the starch granules to absorb water than in a low water content medium where they have to compete to a much greater extent with the protein network. In a low water content medium the swelling would therefore be delayed or limited and occur at a higher temperature [33]. Therefore, most probably the highest IWC (40\%) of the A sample allowed to form a physical network that obstructed the starch release in the cooking water. Moreover, also the thermal treatment to which the dough samples were subjected during the kneading process may promote the formation of a strong physical network, responsible for the lower starch release in the cooking water. In fact, the surface response plot showed in Figure 2 highlights that the overall quality of cooked spaghetti increases with the increase of both IWC and steam injection time. High values of bulkiness and adhesiveness were found also for the $D$ and $G$ samples confirming what was said above on the effect of the highest IWC and the thermal treatment on these attributes.

\section{Conclusion}

The rheological properties of dough based on maize and

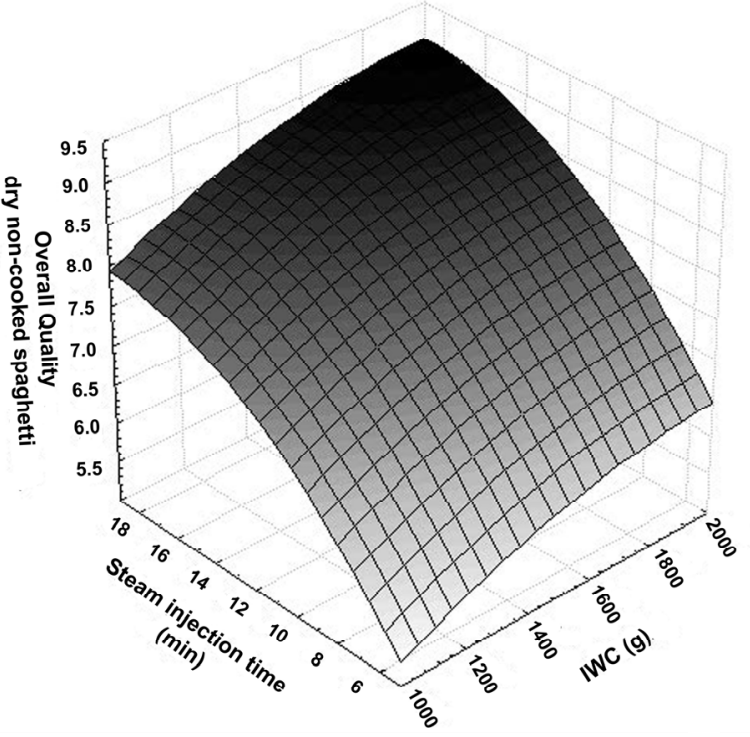

(a)

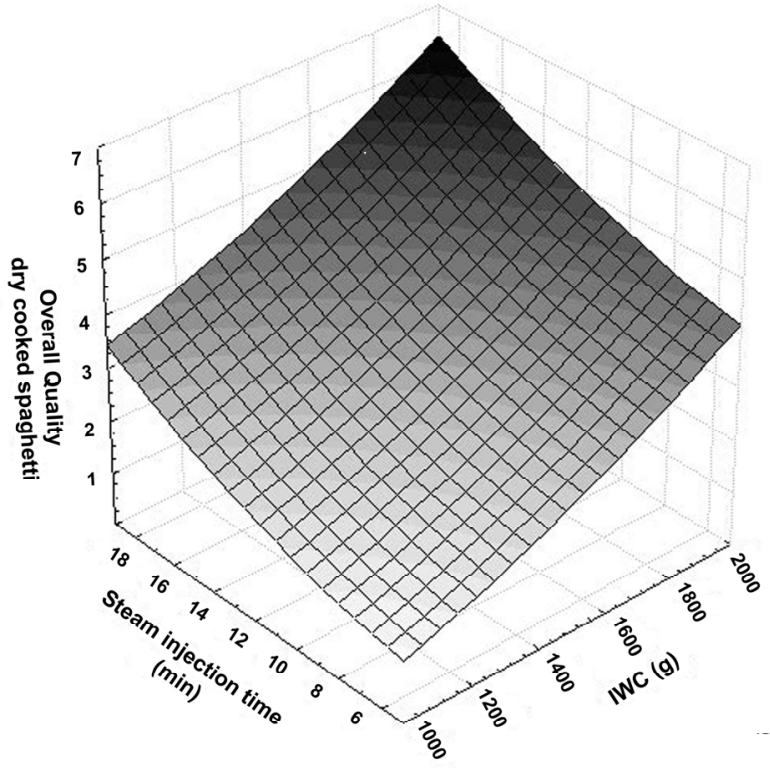

(b)

Figure 2. Effect of the interaction IWC-Steam injection time on the overall quality of dry non-cooked (a) and cooked (b) spaghetti samples.

chickpea flours and the sensorial attributes of the manufactured dry spaghetti as affected by the initial water content and the steam injection time were evaluated in this work. Results highlight that high IWC has softening effect; therefore, dough with higher firmness was obtained with an intermediate value of IWC and steam injection time. Regarding the sensorial properties, all the non-cooked dry spaghetti samples had a very positive score of overall quality with the exception of the samples with the highest IWC and the lowest steam injection time that were scored just above the acceptability threshold 
because of the low resistance to break value. Moreover, the overall quality of the cooked spaghetti showed values around the acceptability threshold, because of low bulkiness and adhesiveness values, with the exception of the sample with the highest IWC that significantly differed from the other samples showing an acceptable score. In conclusion, high IWC permits to improve bulkiness and adhesiveness of the cooked spaghetti, but on the other hand it worsens the texture of dry spaghetti. Surface response plots showed that the overall quality of the cooked and non-cooked spaghetti samples increased with the increase of both IWC and steam injection time confirming the importance of the available water content in the dough and the thermal treatment on the pasta overall quality. In any case, the manufactured pasta demonstrated a good compromise between product quality and nutritional composition. Therefore, they could be a suitable alternative to conventional gluten free pasta based on their superior nutritive; moreover, it is competitive with that already on the market.

\section{Acknowledgements}

This research work, which falls into the Strategic Project "Process innovation for production of functional pasta", PS_003 was financially supported by the Apulia Region.

\section{REFERENCES}

[1] E. Agnesi, "The History of Pasta," In: J. E. Kruger, R. B. Matsuo and J. W. Dick, Eds., Pasta and Noodle Technology, American Association of Cereal Chemists, 1996, pp. 1-12.

[2] P. Feillet and J. E. Dexter, "Quality Requirements of Durum Wheat for Semolina Milling and Pasta Production,” In: J. E. Kruger, R. R. Matsuo and J. W. Dick, Eds., Pasta and Noodle Technology, AACC Inc, St. Paul, 1996, pp. 95-123.

[3] J. A. Wood, I. L. Batey, R. A. Hare and M. J. Sissons, "A Comparison of Australian and Imported Spaghetti," The 34th Annual AIFST Australian, Vol. 53, 2001, pp. 349354.

[4] A. Debbouz and C. Doetkott, "Effect of Process Variables on Spaghetti Quality," Journal of Cereal Chemistry, Vol. 73, 1996, pp. 672-676.

[5] J. E. Dexter and R. R. Matsuo, "The Effect of Gluten Protein Fractions on Pasta Dough Rheology and Spaghetti Making Quality," Cereal Chemistry, Vol. 55, 1978, pp. 44-57.

[6] H. M. Lai, "Effects of Rice Properties and Emulsifiers on the Quality of Rice Pasta," Journal of the Science of Food and Agriculture, Vol. 83, 2001, pp. 203-216.

[7] J. Huang, S. Knight and C. Goad, "Model Prediction for Sensory Attributes of Non-Gluten Pasta," Journal of Food Quality, Vol. 24, No. 6, 2001, pp. 495-511.

\section{doi:10.1111/j.1745-4557.2001.tb00626.x}

[8] B. Mollet and I. Rowland, "Functional Foods: At the Frontier between Food and Pharma," Current Opinion in Biotechnology, Vol. 13, No. 5, 2002, pp. 483-485. doi:10.1016/S0958-1669(02)00375-0

[9] K. Menrad, "Market and Marketing of Functional Food in Europe," Journal of Food Engineering, Vol. 56, No. 2-3, 2003, pp. 181-188. doi:10.1016/S0260-8774(02)00247-9

[10] L. Alvarez-Jubete, H. Wijngaard, E. K. Arendt and E. Gallagher, "Polyphenol Composition and in Vitro Antioxidant Activity of Amaranth, Quinoa Buckwheat, and Wheat as Affected by Sprouting and Baking," Food Chemistry, Vol. 119, No. 2, 2010, pp. 770-778. doi:10.1016/j.foodchem.2009.07.032

[11] C. Reyes-Moreno, E. O. Cueva-Rodriguez, J. MilanCarrillo, O. G. Cardenas-Valenzuela and J. Barron-Hoyos, "Solid State Fermentation Process for Producing Chickpea (Cicer arietinum L) Tempeh Flour. Phisicochemical and nutritional Characteristics of the Product," Journal of the Science of Food and Agriculture, Vol. 84, No. 3, 2004, pp. 271-278. doi:10.1002/jsfa.1637

[12] A. D. Roman-Gutierrez, S. Guilbert and B. Cuq, "Distribution of Water between Wheat Flour Components: A Dynamic Water Vapour Adsorption Study," Journal of Cereal Science, Vol. 36, No. 3, 2002, pp. 347-355. doi: $10.1006 /$ jers. 2002.0470

[13] E. A. Abou Arab, I. M. F. Helmy and G. F. Bareh, "Nutritional Evaluation and Functional Properties of Chickpea (Cicer arietinum L.) Flour and the Improvement of Spaghetti Produced from Its," Journal of American Science, Vol. 6, No. 10, 2010, pp. 1055-1072.

[14] O. Paredes-Lopez, S. O. Serna-Saldivar and S. H. Guzman-Maldonado, "Los Alimentos Màgicos de las Culturas Indìgenas de México-El Caso de la Tortilla," El Colegio de Sinaloa, Culiacàn, Sinaloa, 2000.

[15] V. Hegarty, "Proteins-Meat, Fish, and Other Protein Sources,” Eagan Press, St. Paul, 1995, pp. 197-225.

[16] N. L. Kent and A. D. Evers, "Technology of Cereals," 4th Edition, Elsevier Science, Oxford, 1994. doi: $10.1533 / 9781855736603$

[17] E. Marconi and M. Carcea, "Pasta from Non Traditional Materials," Cereal Foods World, Vol. 46, 2001, pp. 522530.

[18] M. C. Anon, "Hydrocolloids Improve Shelf-Life and Moisture Retention of Shelfstable Bagels," Food Technology, Vol. 56, 2002, p. 50.

[19] P. W. Gras, H. C. Carpenter and R. S. Anderssen, "Modeling the Developmental Rheology of Wheat Flour Dough Using Extension Test," Journal of Cereal Science, Vol. 31, No. 1, 2000, pp. 1-13. doi:10.1006/jers.1999.0293

[20] R. Hoover and H. Manuel, "The Effect of Heat-Moisture Treatment on the Structure and Physicochemical Properties of Normal Maize, Waxy Maize, Dull Waxy Maize and Amylomaize V Starches," Journal of Cereal Science, Vol. 23, No. 2, 1996, pp. 153-162. doi: $10.1006 /$ jers. 1996.0015

[21] R. Hoover and H. Manuel, "Effect of Heat-Moisture Treatment on the Structure and Physicochemical Proper- 
ties of Legume Starches," Food Research International, Vol. 29, No. 8, 1996, pp. 731-750. doi:10.1016/S0963-9969(97)86873-1

[22] S. A. McGlashan and M. E. Mackay, "Comparison of Entry Flow Techniques for Measuring Elongation Flow Properties," Journal of Non-Newtonian Fluid Mechanics, Vol. 85, No. 2-3, 1999, pp. 213-227. doi:10.1016/S0377-0257(98)00189-X

[23] M. A. Bertuzzi, M. Armada and J. C. Gottifredi, "Physicochemical Characterization of Starch Based Films," Journal of Food Engineering, Vol. 82, No. 1, 2007, pp. 17-25. doi:10.1016/j.jfoodeng.2006.12.016

[24] S. Chillo, J. Laverse, P. M. Falcone and M. A. Del Nobile, "Effect of Carboxymethylcellulose and Pregelatinized Corn Starch on the Quality of Amaranthus Spaghetti," Journal of Food Engineering, Vol. 83, No. 4, 2007, pp. 492-500. doi:10.1016/j.jfoodeng.2007.03.037

[25] C. J. Carriere, "The Effect of Amylose Content from Differing Botanical Sources on the Nonlinear Viscoelastic Properties of Semidilute Solutions of Maize Starches," Journal of Applied Polymer Science, Vol. 73, No. 12, 1999, pp. 2429-2436. doi:10.1002/(SICI)1097-4628(19990919)73:12<2429::AI D-APP11>3.0.CO;2-B

[26] C. Letang, M. Piau and C. Verdier, "Characterization of Wheat Flour-Water Doughs. Part I: Rheometry and Microstructure," Journal of Food Engineering, Vol. 41, No. 2, 1999, pp. 121-132. doi:10.1016/S0260-8774(99)00082-5

[27] B. Berton, J. Scher, F. Villieras and J. Hardy, "Measure- ment of Hydration Capacity of Wheat Flour: Influence of Composition and Physical Characteristics," Powder Technology, Vol. 128, No. 2-3, 2002, pp. 326-331. doi:10.1016/S0032-5910(02)00168-7

[28] F. Hsieh, I. C. Peng, A. D. Clarke, S. J. Mulvaney and H. E. Huff, "Restructuring of Mechanically Deboned Turkey by Extrusion Processing Using Cereal Flours as the Binder," Lebensmittel-Wissenschaft und Technologie, Vol. 24, 1991, pp. 139-144.

[29] J.-L. Doublier, "Rheological Studies on Starch-Flow Behavior on the Wheat Starch Paste," Stärke, Vol. 33, 1981, pp. 415-420.

[30] V. J. Morris, "Starch Gelation and Retrogradation," Trends in Food Science and Technology, Vol. 1, 1990, pp. 2-6. doi:10.1016/0924-2244(90)90002-G

[31] A. M. Hermannson and K. Svegmark, "Developments in the Understanding of Starch Functionality," Trends in Food Science and Technology, Vol. 7, No. 11, 1996, pp. 345-353. doi:10.1016/S0924-2244(96)10036-4

[32] G. Della Valle, A. Buleon, P. J. Carreau, P. A. Lavoine and B. Vergnes, "Relationship between Structure and Viscoelastic Behaviour of Plasticized Starch," Journal of Rheology, Vol. 42, No. 3, 1998, pp. 507-525. doi: $10.1122 / 1.550900$

[33] K. Thorvaldsson, M. Stading, K. Nilsson, S. Kidman and M. Langton, "Rheology and Structure of Heat-Treated Pasta Dough: Influence of Water Content and Heating Rate," Lebensmittel-Wissenschaft \& Technologie, Vol. 32, 1999, pp. 154-161. 